\title{
El cine amazónico peruano en la primera mitad del siglo XX
}

\section{Peruvian Amazonian filmmaking in the first half of the 20th century}

Verónica Boggio Lozada ${ }^{1}$

Universidad Autónoma de Barcelona

Pontificia Universidad Católica del Perú

\section{Resumen}

La historia del cine peruano es aún una narración inconclusa con muchas páginas perdidas. Este artículo es un esfuerzo inicial que elabora una cronología descriptiva del cine realizado en la Amazonia peruana desde sus inicios hasta la primera mitad del siglo XX. Se transita a través de las primeras grabaciones y proyecciones, y luego se resalta el rol de los pioneros del registro cinematográfico de esta zona, incluidos peruanos y extranjeros de acuerdo con su relevancia histórica. Se hace también una exploración del contexto histórico en el que cual fueron creadas estas producciones.

1 Dirección, Dinamo Conceptos Culturales.

Contacto: veronicaboggio@gmail.com 
Palabras clave: Amazonía, Perú, selva, cine, historia, cronología, siglo XX

\begin{abstract}
The history of Peruvian cinema is still an unfinished narrative ridden with lost pages. This article is an initial effort that elaborates a descriptive chronology of the films made in the Peruvian Amazon from its beginnings to the first half of the 20 th century. It goes through the first recordings and projections and then highlights the role of the pioneers of the cinematrographic record of this area, including Peruvians, and foreigners according to their historical relevance. It also explores the historical context in which these productions were created.
\end{abstract}

Key words: Amazonia, Peru, jungle, filmmaking, history, chronology, 20th century.

\title{
Introducción
}

La selva amazónica ha tenido siempre un reflejo enigmático en nuestro imaginario. Ha sido pensada como un lugar impenetrable o indescifrable, un lugar donde suceden "otras"

120 realidades. Es un paisaje único, que no puede compararse con otros lugares del mundo, inclusive con otros bosques tropicales. Los relatos sobre su diversidad biológica y sobre quiénes la habitan siguen nutridos de visiones fantásticas o idealizadas. Un ejemplo de ello es la construcción que se hace sobre "lo salvaje", su relación con lo primigenio u originario, y la necesidad de civilizarlo. Este discurso en su momento justificó la colonización y dominio de estos 
grupos humanos, y sigue haciéndolo hasta la actualidad de distintas formas.

Las narraciones que construimos sobre la realidad amazónica se nutren de historias que encontramos en el cine y en otros productos culturales como la literatura, la pintura o la fotografía. En este sentido, es importante recapitular la memoria sobre estas historias y, a la vez, tener una visión crítica de su construcción. La intención es reseñar la producción cinematográfica partiendo de una cronología descriptiva del cine realizado en la Amazonía peruana en la primera mitad del siglo XX y relacionarla con los contextos históricos, políticos, sociales y culturales que definieron su producción. Interesa conocer el "detrás de cámara", así como la intención del por qué y el para qué fueron hechas estas producciones. Es complejo o casi imposible pretender realizar un análisis de la representación generada a partir de estas producciones cinematográficas, simplemente porque la mayoría de ellas no se encuentran disponibles o ya no existen. Sin tener la posibilidad de ver estas imágenes, es improbable realizar el análisis de sus formas de representación.

Esto nos remite a la situación actual del acervo documental específico sobre la historia del cine peruano, pues no solo hay escasa recopilación de los hechos sucedidos, sino también carencia de archivos cinematográficos y de instituciones que recopilen, preserven y recuperen el patrimonio cinematográfico y audiovisual. Como se ha mencionado, la mayoría del material fílmico de esta primera época no existe y solo se conservan descripciones publicadas en la prensa. En otros casos, es posible que estén esperando ser descubiertos en algún mercadillo local o alguna biblioteca familiar como ha sucedido con el álbum de fotografías del viaje de la comisión 
consular a los territorios del cauchero Julio César Arana en 1912, publicado en 2013 por Chirif, Cornejo Chaparro y De la Serna Torroba. ${ }^{2}$

En el contexto latinoamericano, esta situación muestra el atraso que tenemos en cuanto a políticas públicas culturales que promuevan la creación y mantenimiento de archivos nacionales del patrimonio cinematográfico. En nuestro país encontramos algunas iniciativas privadas con poco éxito, como es el caso del Archivo Peruano de Imagen y Sonido (Archi) ${ }^{3}$ o la antigua Filmoteca de Lima; ${ }^{4}$ sin embargo, es importante relevar el estado de emergencia de esta situación y la necesidad de una participación estatal activa en el establecimiento de archivos de estas características.

Ante esta problemática, cabe preguntarse qué se entiende por cine amazónico peruano. Esta revisión se ha centrado en la producción cinematográfica hecha en la amazonia peruana desde los orígenes del cine, a finales del siglo XIX, hasta la mitad del siglo XX. Se ha tomado en cuenta las produccio-

2 Este álbum fue encontrado de manera casual por el periodista loretano Jaime Vásquez Valcárcel hace algunos años y publicado en el año 2013 por los autores citados; estuvo perdido por cerca de 100 ańos sin que nadie pudiera relevar su importancia.

3 El Archivo Peruano de Imagen y Sonido (ARCHI) es un proyecto privado fundado por Irela Núnez del Pozo y Mario Lucioni en 1991 para apoyar el proceso de recuperación de dos mil rollos de película de nitrato de la Biblioteca Nacional del Perú. Está focalizado en salvaguardar el archivo fílmico del cine peruano y cuenta con algunas colecciones importantes.

4 La Filmoteca de Lima fue gestionada en su momento por un consejo consultivo presidido por Isaac León Frías a través del patronato del Museo de Arte de Lima (MALI). Este archivo ha sido asumido por la Universidad Católica del Perú desde el 2003. 
nes realizadas por peruanos y extranjeros de acuerdo con su relevancia histórica y se ha considerado, sobre todo, a los pioneros del cine en esta región del país.

\section{Los primeros momentos del cine en la Amazonía peruana}

Desde finales de la década de 1880 hasta los primeros dos decenios del siglo XX las zonas amazónicas sufrieron una gran transformación gracias al auge del caucho. Esta gran revolución económica, que vino de la mano del crecimiento de la industria automovilística y del uso del neumático, transformó a esta región en términos culturales, sociales y geopolíticos. Trajo consigo el desarrollo de nuevos e importantes focos urbanos, como la actual ciudad de Manaos en Brasil o la de Iquitos en Perú, asentamientos habitados por una nueva burguesía europea que buscó satisfacer los gustos más refinados de la época.

En ese contexto, hacia finales del siglo XIX, apareció paralelamente el cine. La primera proyección se realizó en París, gracias a los hermanos Lumier, el 28 de diciembre de 1895. Cinco años después, en 1899, se proyectaron las primeras imágenes registradas en territorio amazónico en el Teatro Politeama de Lima (Bedoya, 2009, p. 46). El historiador de cine Ricardo Bedoya relata que esta proyección fue llamada "Programa de vistas tomadas al natural", la cual incluía tres cortometrajes llamados: Catedral de Lima, Camino a la Oroya y Chanchamayo; películas proyectadas con un aparato llamado estereokinematógrafo, de la casa parisina Lumier, el cual funcionaba a través del sistema de imágenes móviles (p. 46). No es difícil presumir que el contenido de las cintas estaría relacionado con los títulos de cada cortometraje. 
Es de suponer que estas imágenes correspondieron con lo que luego fue llamado "cine documento", práctica común en los primeros ańos del cine en donde se realizaban registros de la realidad, normalmente con tomas de un solo plano sin un punto de vista específico. Actualmente, se enmarca a este periodo como los orígenes del documental dentro del género cinematográfico. En esta línea, la casa Lumier se dedicó por esos años al registro de imágenes llamadas "películas de actualidad" y enviaba a un gran grupo de operadores a diferentes puntos del globo para documentar lugares y hechos. Se desconoce si algunos de estos operadores fueron los que registraron las imágenes de esa primera proyección en el Perú, pues no existen registros de quién las grabó ni se cuenta con las copias de estas películas.

Paralelamente a esta actividad en Lima, se iniciaron también los primeros hechos cinematográficos registrados en la selva peruana, específicamente en la ciudad de Iquitos. Como antecedente, Luis Navarro Cáuper cuenta que un par de años antes, en 1898, Clemente Alcalá y Francisco de Paula Secada decidieron poner un espacio para el espectáculo y la distracción en la plaza principal de Iquitos llamado el "Alhambra", en donde colocaron un carrusel de juegos traído de Manaos. Cuatro ańos más tarde, este espacio se convirtió en el primer cine de la ciudad con un equipo de proyecciones de la casa

124 Lumier, gracias a la gestión de Eduardo Fuller (2002, p. 56). Fue en el año 1900, según este mismo autor, cuando se realizó la primera proyección de cine en esta ciudad en la planta baja de la conocida Casa de Fierro construida por Eiffel, propiedad en esos años de Manuel Montoya (2002, p. 56).

En esos ańos Iquitos estaba en plena ebullición por el auge del caucho e incrementaba el comercio y tráfico de produc- 
tos desde y hacia Europa. Esto trajo consigo un cambio en las costumbres y consumo cultural de los habitantes de la ciudad, incluido el nuevo espectáculo del cine. Cabe recordar que en sus primeros años el cine fue considerado un espectáculo de circo o de feria y se presentaba como parte de los juegos de carrusel junto a personajes exóticos, y tenía menor importancia en el consumo de las clases acomodadas de la época. Fue en el primer decenio del siglo XX que las empresas productoras impulsaron el cine como lo conocemos actualmente. En 1905, Arnaldo Reátegui, un empresario migrante de San Martín se asoció con Luis Pinasco y viajó a Francia para comprar una máquina de proyecciones y películas de la casa Pathé Fèrges y Gaumont para montar un cine en Iquitos que se llamó "Jardín Strassburgo", ubicado en la actual calle Sargento Lores (Navarro Cáuper, 2002, p. 56). Si bien se dieron estos registros cinematográficos y proyecciones desde 1899, no fue hasta casi el final del decenio de 1900 que la producción de documentales se generó de manera regular.

Otro contexto histórico retratado de ese periodo fueron las gestas militares del conflicto con Colombia. En Iquitos, el empresario Armando Reátegui continuó realizando distintas inversiones y en 1911 se lanzó a hacer un registro de la gesta del Caquetá ${ }^{5}$ y filmó la llegada de las tropas del comandante Benavides a la ciudad de Iquitos y a la frontera con Colombia (Bardales, 2014, p. 241). Por su parte, el comandante Benavides hizo diversos registros del contexto militar de la época y describió la Entrada a Iquitos de las tropas que participaron en el combate del Caquetá en 1915, el Picnic durante los carnava-

5 Se le llamó de esta manera a diversos enfrentamientos que se registraron entre fuerzas peruanas y colombianas por la lucha de la frontera amazónica en el ańo 1911. 
les de 1914 en Iquitos y la Revista de la vida militar y social de Iquitos (Bedoya, 2009, p. 127).

\section{La conquista de la selva central a través del registro cine- matográfico}

Debemos enmarcar la conquista de la selva en el periodo del presidente Nicolás de Piérola y, sobre todo, contextualizarlo en su política de colonización de la selva. La visión de Piérola era fomentar la migración de extranjeros a las zonas "vacías" de la geografía peruana con el objetivo de lograr el desarrollo del país (Bedoya, 2009, p. 46).

En ese contexto, la construcción de ferrocarriles fue crucial para el desarrollo de esta idea, lo que se convirtió no solo en un reto de infraestructura a causa de la compleja geografía nacional, sino también en una necesidad urgente. El proceso de desarrollar vías de acceso al interior del país se daba desde 1851, cuando se impulsó la construcción del ferrocarril central, una de las obras de ingeniería más complejas de la época, que pasó por la dirección de diversas empresas y demoró un promedio de 38 años en lograrse.

Los protagonistas de este proceso fueron políticos y empresarios que buscaron plasmar su visión o mostrar la hazaña que implicaba la construcción de este tipo de infraestructura, por lo que muchos utilizaron el poder de la imagen para exponer sus logros a la posteridad. Como señala Bedoya, desde la segunda mitad del siglo XIX muchos empresarios utilizaron la fotografía para este fin, Henry Meiggs, por ejemplo, documentó a través de una cámara fotográfica la construcción de este ferrocarril (1997, p. 15). Como se puede deducir, en la 
primera mitad del siglo XX la fotografía fue reemplazada por el cine con el mismo fin.

La ruta del ferrocarril central fue una de las más registradas y representadas en esta primera época del cine amazónico. Ejemplo de ello es Chanchamayo, el primer cortometraje registrado y proyectado sobre la selva peruana, mencionado en líneas anteriores. Luego, la producción The Chuncho Indians of the Amazon River realizada en 1910 por la empresa estadounidense Edison Manufacturing Company, en ella se mostraban imágenes del río Perené (Bedoya, 1997, p. 16).

En ese mismo año, la selva central volvió a ser la protagonista. Bedoya menciona la proyección del primer largometraje documental llamado Viaje al interior del Perú, filmada por el norteamericano C. L. Chester y proyectada en cinco partes en octubre de ese año. La película mostraba el recorrido del ferrocarril central que partía desde el Callao y luego atravesaba Chanchamayo, Huancayo, el Perené, el Mantaro, Cerro de Pasco y Morococha. Solo han quedado registrados los comentarios periodísticos de la prensa de la época:

[...] pueblos y costumbres, curiosidades y bellezas, todo está ahí reproducido con gran fidelidad y gusto artístico; desde los indios hilando y tejiendo, desde los campos de trigo fecundados por los arados de los bueyes, hasta los puentes colgantes, las manadas de llamas, los célebres campas de las montańas y los surcadores adiestrados en los ríos caudalosos (La Prensa, 6 de octubre 1910, citado por Bedoya, 1997, p. 15).

La película tuvo una duración de 120 minutos y fue producida por la Peruvian Corporation, conocida empresa inglesa encargada de gestionar los ferrocarriles del país. La visión 
empresarial era la que impulsaba el retrato de la Amazonía y su presentación para plasmar en estas imágenes su visión, sus objetivos y sus logros.

Once años más tarde, en agosto de 1921, nuevamente la selva y el ferrocarril central fueron retratados, esta vez con un objetivo diferente motivado por la investigación. En ese año, se proyectó la película Expedición cientifica sueco-peruana a las montañas del oriente; Bedoya la menciona como una crónica filmada de la expedición organizada por Carlos Rospigliosi Vigil y el científico sueco Otto Nordenskjold, realizada por la productora Cinematográfica Sudamericana y grabada por el comandante G. M. Dyott (2015). La cinta se exhibió en el Teatro Forero en una velada a beneficio del Ministerio de Instrucción, ${ }^{6}$ acompañada por un recital poético de José Santos Chocano. La prensa de la época la describe de la siguiente manera:

Verán todo el curso del viaje que duró siete semanas. Saliendo de Lima, veremos los pintorescos paisajes recorridos por el ferrocarril central, los precipicios, puentes, túneles, los nevados picos de los Andes. Atravesando la Cordillera de los Andes, bajarán en plena región de la montaña con su flora y fauna tropicales, visitarán Pachacayo, Tarma, la colonia del Perené, Cerro de la Sal, Río Perené, el Pangoa, Río Tambo, Río Paucartambo, Puerto Ocopa, Río Negro, San Antonio, etc. Podrán también darse cuenta de la vida de los indios llamados "chunchos", medio salvajes de los campas, su música, sus defensas y costumbres [...] (El Comercio, 21 de agosto de 1921, citado por Bedoya, 2015).

6 Llamado Ministerio de Instrucción Pública, Beneficencia y Negocios Eclesiásticos que luego pasó a ser el actual Ministerio de Educación del Perú. 


\section{El rol pionero de los evangelizadores}

Otros pioneros y protagonistas de la exploración de la Amazonia fueron las órdenes religiosas, quienes desde la época de la colonia establecieron sus vínculos con esta remota región. En el siglo XX, muchas de estas órdenes mantuvieron misiones en diferentes partes del país y no tardaron en utilizar el registro cinematográfico para su labor evangelizadora. A pesar de ello, existen muy pocos registros en fuentes secundarias sobre las producciones que realizaron las diferentes misiones durante este periodo. No hay información precisa del material cinematográfico existente o de las órdenes que se dedicaron a esta labor.

El documentalista e investigador amazónico Fernando Valdivia (2014) señala, por ejemplo, que en la primera mitad del siglo XX fueron muy populares los llamados rollos catequésicos producidos por los misioneros dominicos (p. 182). Valdivia también señala que el padre Gerardo Fernández, de esta misma orden, en 1924 emprendió la filmación de las labores misioneras en la selva de Cuzco. Para ello, se encaminó a la zona del Alto Urubamba, cerca de Koribeni y junto al padre Wenceslao Fernández, con quien estaba emparentado, filmaron un documental con los nativos de la misión (p. 182). La película trata sobre misioneros que se pierden en la selva al decidir salir a buscar nativos; en el proceso se les aparece Santa Rosa de Lima y luego de ello logran convertir a los nativos y fundar una nueva misión. La película se llamó Misiones Dominicas del Perú y fue grabada con una cámara de la casa Pathé y proyectada por primera vez en el santuario de Santa Rosa de Lima y luego en el Teatro Forero el 6 de junio de 1927. La película tuvo un gran éxito y fue llevada a la Exposición Universal de Misiones de 
Barcelona en 1929, a partir de lo cual pudo se proyectada en diversos países (p. 182).

Por su parte, los franciscanos hacían desde el siglo XIX constantes expediciones hacia la cuenta del Pachitea y el Pozuzo, y utilizaban como base el convento de Ocopa en la región de Junín (Bedoya, 1997, p. 59). El 17 de abril de 1929 se estrenó en el cine Excélsior de Lima la película La conquista de la selva, realizada por Guillermo Garland junto a Fray Bernandino Idoyaga para promover el trabajo de estos misioneros; la película fue mostrada en la Exposición de Sevilla en esos años (p. 59). La prensa de la época la describe de esta manera:

[...] han filmado una cinta que tiene gran interés porque da a conocer la belleza y la fecundidad de las tierras de las zonas de Pampa Hermosa, Satipo, Perené, Ene, Tambo, Urubamba, Alto Ucayali y Pachitea, hasta el puerto de Iquitos, capital del departamento de Loreto. Se aprecia en esta interesante exhibición, lo mismo las colonias fundadas por los misioneros en diversos lugares cercanos a Ocopa como las ricas tierras bañadas por las afluentes del Ucayali y las situadas a lo largo de este río hasta su desembocadura en el monarca fluvial (La Crónica 16 de abril de 1929, citado por Bedoya, 1997, p. 59).

Bedoya también comenta que esta película tuvo el apoyo del presidente Leguía para su producción, y del vicariato de Uca-

130 yali a través del monseñor Francisco Irasola y de la autoridad provincial de los padres descalzos Buenaventura Uriarte. Una crítica de la época narra lo siguiente:

[...] la cinta fue hecha con criterio informativo y dirigida por los buenos padrecitos misioneros que, ante todo se han querido poner en evidencia. Apenas si se nos muestra las costumbres y la vida de los naturales de aquellas regiones; apenas si vislumbramos todo el tesoro de poesía y de fuerza 
que son los bailes, las fiestas, la existencia familiar de esos hermanos nuestros de la "montaña" [...] (María Wiesse, Revista Amauta, No. 23, mayo de 1929, citado por Bedoya, 1997, p. 59).

\section{La colonización de las imágenes: Silvino Santos y Julio César Arana}

El boom del caucho, que se dio pasada la segunda mitad del siglo XIX y que llegaría hasta principios del XX, centraba la mirada de inversionistas europeos y americanos en la Amazonía enfocados en una visión capitalista y en la extracción de recursos para la producción masiva. Mientras tanto, los intereses de la capital y la política centralista se focalizaban en la costa, sin mirar detenidamente lo que ocurría en otras partes del país.

Uno de los más importantes y controvertidos empresarios caucheros de la época fue Julio César Arana. Nacido en la provincia de Rioja, en el departamento de San Martín, comenzó su trabajo en Tarapoto, donde explotó el caucho desde 1881 en la zona de Yurimaguas para luego trasladarse a la ciudad de Iquitos e introducirse en las regiones del Putumayo y el Caquetá, entre Colombia y Perú. Ante la ausencia del Estado, fue pionero en esas zonas y estableció su imperio cauchero. Tuvo diversas empresas e inversiones y llegó a ser el principal accionista de la Peruvian Amazon Rubber Company, empresa fundada en Londres con la que logró captar grandes capitales británicos (Chirif, Cornejo Chaparro y De la Serna Torroba, 2013, p. 244).

En ese contexto, en 1907 aparecieron las primeras denuncias de maltratos, asesinatos y esclavismo formuladas por el 
periodista Benjamín Saldaña Rojas en los periódicos iquiteños La Felpa y La Sanción (Chirif et al., 2013, p. 16). Al parecer, Arana utilizaba esa estrategia para abaratar los costos de la mano de obra en la extracción del caucho. A pesar de esas primeras declaraciones en la prensa peruana, el caso no tuvo mayor repercusión en el contexto político o legal peruano hasta la intervención de los medios británicos. Dos años más tarde, el periódico londinense The Truth, a través de un artículo del norteamericano Walter Handerburg, publicó esa misma historia. Este hecho suscitó un escándalo internacional de grandes dimensiones, que luego sería recordado por la historia como "los escándalos del Putumayo" y traería como consecuencia la apertura de una investigación por parte de la Foreign Office a la que le siguió un proceso similar en el Perú.

Silvino Santos Silva era un portugués que había recorrido en esos años diversas regiones de Brasil, como Belém do Pará, el Xingú, el Alto Guamá e, inclusive, Iquitos en el Perú. En ese proceso conoció a Leonel Rocha, quien sería su maestro en el aprendizaje de la pintura y la fotografía (Vale da Costa, 1987, p. 20). Era muy joven en esos tiempos y a los 17 años decidió regresar a Portugal, donde perfeccionó esas artes para volver luego de un ańo y asentarse definitivamente en la ciudad de Manaos en 1910. Por aquellos tiempos, Manaos era una ciu-

132 dad en ebullición gracias a la explotación del caucho, con gran influencia europea por las rutas de intercambio que se establecían y con una nueva oligarquía que se había asentado en esta ciudad (p. 20).

En Manaos, Silvino abrió un estudio de fotografía por el que se hizo conocido. Martín Brañas cuenta lo siguiente: "Silvino Santos había demostrado tener dotes idóneas para ser un 
gran fotógrafo. La instalación de su estudio particular pronto le proporcionaría una buena fama como fotógrafo, no solo en la cuidad de Manaos, sino también en Belem do Pará y en la peruana ciudad de Iquitos" (Chirif et al., 2013, p. 16). Es así que en el año 1912 fue invitado por el cónsul peruano en Manaos D. Carlos Rey de Castro para hacer un registro fotográfico de los indios amazónicos en un viaje de la comisión de visita de las autoridades por el río Putumayo. En este viaje participaron, además de D. Carlos Rey de Castro, el cónsul de Estados Unidos en Iquitos E. J. Fuller y el de Inglaterra George B. Michell. En último momento, también se integró Julio César Arana a la travesía (p. 21).

En ese viaje, que duró tres meses, recorrieron todas las estaciones caucheras de la zona y en la travesía Arana conoció a Silvino Santos. Las fotografías tomadas por Santos, que fueron reveladas en las oficinas de la empresa de Arana en Iquitos y llevadas luego a Londres, han sido mostradas en la publicación Álbum de fotografias: viaje de la comisión consular al río Putumayo y afluentes, mencionada en el inicio de este artículo. Estas fotografías dan cuenta de la mirada inicial de Santos sobre los indígenas, una visión estática que se encuentra muy lejos de buscar retratarlos desde su propia mirada o contexto. Para este caso, Chirif, Cornejo Chaparro y De la Serna Torroba realizan un análisis crítico de la representación propuesta por Santos, “[...] el huitoto, bora u ocaina es indivisible del bosque, compenetrado con la selva. La mirada colonial lo confunde con el follaje, y sus cualidades humanas, sociales, culturales son trastocadas para dar lugar a la predominancia de Occidente en la narrativa de esta época” (2013, p. 10).

Por esos años Julio César Arana vivía en Europa, donde comprobó el impacto del nuevo medio cinematográfico. Así, en 
1913 decidió contratar a Silvino Santos para una labor pionera, hacer una película sobre la Amazonia en el río Putumayo con el fin, por supuesto, de fundamentar su defensa en Londres frente a las acusaciones a las que hacia frente y limpiar su nombre (Chirif et al., 2013, p. 16). Tomando en cuenta que Silvino no era un operador de cine, Arana invierte en él y lo envía a París para que aprenda ese oficio. Allí, Silvino realizó estudios de la casa Pathé Fèrges y en el laboratorio de los hermanos Lumier durante tres meses. Arana compró una máquina de la casa Pathé y dos mil metros de negativo elaborado con una emulsión especial para las temperaturas de la caliente selva amazónica (p. 16).

$\mathrm{Al}$ volver, Silvino se internó en la selva para hacer los registros cinematográficos con el objetivo de realizar la película encargada. En el primer trayecto conoció a la ahijada de Arana, Ana María Shermuly, con quien se casó el 30 de agosto del mismo año (Chirif et al., 2013, p.16). Durante dos meses viajó para registrar el material con el que elaboró la película, que luego se perdió en 1914, en el naufragio del navío que la transportaba a Europa al ser atacado por flotas alemanas de la Primera Guerra Mundial. ${ }^{7}$

La cinta no pudo ser titulada aún; mostraba las zonas de La Chorrera, Entre Ríos, El Encanto, el río Putumayo e Iquitos.

134 Vale da Costa cuenta que en este film se registraron comunidades de indios huitoto, ocainas, boras, resíngaros, orejones y andokes. En cada sección, los indios fueron llamados para ser filmados. El propio Santos narra:

7 Algunos autores, como Brañas, mencionan que el navío se dirigía a Londres y se hundió en su periplo por el Atlántico, otros, como Vale da Costa, señalan que se dirigía hacia Lima. 
[...] en una tribu de Huitotos avisaron a todos y se reunieron en una gran maloca unos 2000 indios e indias, todos pintados con colores bizarros, una cosa majestuosa, fue la primera y única vez que vi tantos indios reunidos. La fiesta duró tres días y tres noches, filmé y fotografié muchas escenas, las indias pintando el cuerpo de otras, preparando mandioca, muchas, muchas cosas (Romance de minha vida, memorias manuscritas de Silvino Santos, citado por Vale de Costa, 1987, p. 150; la traducción es mía).

Silvino hizo el revelado en un cuarto oscuro que él mismo preparó en la estación de La Chorrera. Al terminar esta experiencia, el fotógrafo volvió a la ciudad de Manaos para asentarse ahí y continuar realizando sus producciones cinematográficas (Vale da Costa, 1987, p. 24). Vale da Costa comenta también que se pudo salvar el material fotográfico que se registró en la misma travesía y algunas pocas imágenes que luego se pudieron ver en la película Los indios witoto del río Putumayo, estrenada el 19 de julio de 1916 en el Teatro Politeama de la ciudad de Manaos, primera película que Silvino proyectó públicamente en su carrera (p. 151).

Ni Julio César Arana ni Silvino Santos se rindieron ante la pérdida del material rodado; Arana formó luego la productora cinematográfica Amazonía Cine Film Company con la que realizó junto a Santos varias películas más. Dentro de ellas está el mediometraje documental Escenas amazónicas, dividido en cuatro partes y filmado en el río Putumayo en 1917 y estrenada el 20 de abril de 1921. Esta película no tuvo buena fortuna, pues tras su estreno fue llevada a Londres en 1920 por Propecio Saravia para su difusión, quien supuestamente la vendió a una empresa de turismo y tras ese acto no se supo más de ella (Vale da Costa, 1987, p. 156). 
Esta pérdida le generó serios problemas económicos a la productora; sin embargo, Arana estaba convencido de que el cine era no solo una herramienta para limpiar su imagen, sino también un gran instrumento para promocionar sus negocios y atraer nuevas inversiones. En noviembre de 1920 se estrenó en el Teatro Politeama de Manaos y al año siguiente en el Teatro Lima una nueva producción realizada por Santos y Arana titulada El oriente peruano. Esta película de 90 minutos no tiene copias existentes; la prensa de la época la comentó de la siguiente manera:

Se aprecia en la película, cuya duración es más o menos de hora y media, los considerables progresos que han hecho la civilización en las rebeldes tribus de nuestra selva; y sobre todo el estado floreciente en que se encuentra la ciudad de Iquitos. Los grandes ríos de Oriente, la enorme vegetación de la selva, las hermosas haciendas en las que trabaja la indiada de distintas tribus ya civilizadas; en fin, todo el conjunto de la película es tan interesante que cautivará al espectador más exigente. También se admira en aquella cinta cinematográfica, las originales y diversas costumbres de los indios según sus tribus, llamando extraordinariamente la atención el tipo característico del salvaje (La Prensa, 23 de mayo de 1921, citado por Bedoya, 1997, p. 32).

Más tarde, el 27 de febrero de 1933, la cinta fue reestrenada en la época del deterioro de las relaciones fronterizas con Colombia. Como prueba de que estas zonas eran patrimonio nacional, los diarios comentaron: "[...] comprobareis que peruanos son los aviones que cruzan raudos y veloces por el cielo del oriente y peruanas son las naves que surcan sus rios; peruanas son sus industrias y su floreciente comercio; peruanos son los capitales allí invertidos; peruanos son sus habitantes aborigenes" (El Comercio, 27 de febrero de 1933, citado por Bedoya, 1997, p. 32). Esta es la película por la cual Santos sería recordado en 
su etapa inicial en la Amazonía peruana, la que constituye de alguna forma los inicios de su carrera como cineasta.

No se registran posteriores colaboraciones entre Santos y Arana; sin embargo, la historia del cine en la Amazonía debe reconocerlos como pioneros y protagonistas. Este caso releva la importancia que tuvo el cine para los intereses comerciales de la época y la forma en que estos impulsaron su aparición y desarrollo. Silvino Santos continuó su carrera como realizador en tierras brasileras. En total, filmó cerca de 12 documentales, incluida la película No país das Amazonas, con la producción de Joaquín Gonzales de Araujo, otro magnate cauchero de la época nacido en Brasil. Con esta película llegó a la cúspide de su fama, pero con el tiempo fue olvidado. No fue hasta 1969, cuando el Grupo de Estudios Cinematográfico de Río de Janeiro, en el marco del Primer Festival Norte de Cine Brasilero, homenajeó a Silvino Santos en este país, donde es actualmente reconocido como el padre del cine amazónico (Chirif et al., 2013, p. 18). Varios años después, en 1979, se realizó una película sobre su vida llamada $O$ cineasta da selva, dirigida por Aurelio Michiles, la cual recrea su vida a través de una docu-ficción que es narrada y protagonizada por un ficticio Silvino Santos que recuerda sus memorias y periplos por la selva (Bustamante, 2014, p. 230).

El crítico Bedoya cuenta que tras la bancarrota de la productora Amazonía Film Company, el incansable Arana se asoció con otros empresarios para formar una nueva productora llamada, irónicamente, La Colonizadora (1997, p. 40). Constituida en 1925, estuvo conformada por importantes empresarios, como los italianos Pascual Chiarella, Hugo Tomenotti, Esteban Campodónico, Esteban Massa, además de Carlos Gonzales, Luis Alberto Blume, Rosendo Badanai y 
Julio Ego Aguirre. La intención de estos empresarios era incentivar sus intereses económicos y utilizar esta plataforma como una manera de hacer campaña para captar inversiones en sus actividades colonizadoras, en otras palabras, deseaban hacer películas de propaganda.

Luego, con esta misma productora se realizó el documental Tras los Andes (hacia el paraíso peruano) en 1925, película filmada por la Empresa Cinematográfica del Perú de Manuel Morales, con la fotografía de Víctor Ludwick. Bedoya cuenta que su objetivo era registrar las faenas de colonización en el oriente peruano por parte de este grupo empresarial. Estos eran los dueños de un millón de hectáreas entregadas en explotación a la denominada Concesión Tomenotti, entre los ríos Ucayali, Palcazu, Pichis y Pachitea. De la película solo se conservan descripciones de su contenido:

Aparece en los primeros cuadros el Presidente Leguía, el mapa nacional, los planos de la Concesión Tomenotti y diversos y bellos aspectos de las obras que se llevan a efecto en el ferrocarril al Ucayali. Bien podría decirse que se hace un recorrido completo por la nueva vía hasta el punto ya concluido de ésta [...] La segunda serie de cuadros comprende a diversos aspectos de los terrenos que forman la Concesión Tomenotti. Se ve en ellos las rancherías de las nuevas colonias, los cultivos iniciados, la feracidad de la tierra traducida en los magníficos frutos que se exhiben, y la vida laboriosa, sencilla y feliz que llevan los colonos [...] Puerto Leguía, centro de las actividades comerciales de toda la colonia, sectores de los grandes ríos que cruzan la zona, escenas de embarque y desembarque en todas las especies de embarcaciones y que surcan los ríos y hasta una elección de Alcalde en Puerto Leguía completan esta parte de la cinta. También se han impresionado algunos cuadros del muelle de Iquitos y partidas de barcos para el Atlántico, calles principa- 
les de la capital loretana [...] (La Prensa, 14 de agosto de 1925, citado por Bedoya, 1997, p. 40).

Un dato curioso es que, al igual que Santos, Arana tuvo también una película basada en su vida. En 1989, el director cusqueño Federico García realizó una película de ficción llamada El socio de Dios, en donde el empresario cauchero es el protagonista, enmarcado en la historia de los "Escándalos del Putumayo" (Bedoya, 1997, p. 32).

\section{Entre 1930 a 1950, el periodo vacío}

La etapa entre 1930 y 1950 es una etapa casi desierta respecto a la producción cinematográfica realizada en la selva peruana; en comparación con otras cinematografías de la región existe muy poca producción o registro sobre esta zona del país. Pero sin lugar a dudas Antonio Wong Rengifo es una figura única en este panorama y, sobre todo, en el ámbito del cine nacional y del cine hecho en las regiones. Nacido en la región de San Martín en 1910, fue hijo de un migrante cantonés y de una moyobambina. Desde pequeño su padre quiso impulsarlo, sin éxito, como comerciante. El padre Joaquín García, historiador español, ${ }^{8}$ decía sobre él, "puede considerarse como uno de los hombres más representativos, si no el mayor, de la cultura amazónica, por su capacidad creadora, su apertura a la incorporación de nuevas técnicas y la inmensa versatilidad de sus posibilidades" (1981, p. 117). No solo es catalogado como pionero del cine amazónico peruano,

8 Español fundador del Centro de Estudios Teológicos de la Amazonia (CETA), institución que alberga la segunda mayor biblioteca amazónica con 35 mil libros en sus registros. 
sino también como formador de este cine por su capacidad de experimentación con las nuevas tecnologías, sobre todo, con las que en su tiempo llegaban de Estados Unidos.

Fue una persona innovadora y apasionada, con un estilo de vida particular, que se dedicó a diferentes ramas de las artes: pasó por la fotografía, la música, el periodismo, el cine e, inclusive, es recordado por sus congéneres de la época por su gran afición al futbol. ${ }^{9}$ Desde muy joven tuvo pasión por la fotografía, la que fue su primera herramienta para documentar y retratar. Años más tarde, en 1924, fue enviado a Europa donde reavivó la vocación por las imágenes que luego, a su regreso, se convirtió en el trabajo de toda una vida. Al casarse con Juana Ferreira decidió poner un estudio fotográfico llamado Foto Wong, donde con el tiempo se volcaría a la cinematografía. Como fotógrafo, exploró "el paisaje amazónico, así como la exposición de la arquitectura de mosaicos y azulejos" (Bardales, 2014, p. 240). Como periodista, fue director desde 1936 de la revista deportiva Loreto Gráfico, experiencia compartida con Rómulo Espinar y Luis Navarro Cáuper, conocido escritor, promotor cultural y posterior biógrafo de Wong.

En 1931 inició su trabajo en el cine y produjo de manera constante durante dos décadas. Comenzó grabando registros

140 de la vida cotidiana de la ciudad de Iquitos y de Loreto, y realizó diversas estampas históricas de sucesos y lugares que

9 Perteneció en este rubro al tradicional club Athletic José Pardo de Iquitos. Según Pedro Carmelo Montalván, citado por Bardales, en 1935 integró la selección oficial del departamento en el torneo nacional. 
unificó luego con el nombre de Revista loretana, ${ }^{10}$ serie de cortometrajes de los cuales se han podido recuperar siete en diversos formatos. Algunos de los títulos más importantes son Frente del Putumayo (1932), Sepelio del sargento Fernando Lores (1933), Inauguración del municipio (1943), Conozca Loreto en tecnicolor (Bardales, 2014, p. 241).

El crítico Francisco Bardales destaca también una serie cinematográfica realizada por Wong basada en escenas capturadas durante la guerra con Colombia, entre 1932 y 1933, producción que consistió en un total de cinco rollos de quinientos metros de longitud aproximadamente (2014, p. 241). Según Navarro Cáuper, parte de estas imágenes fueron proyectadas en Iquitos en 1932 y causaron expectativa por su importancia como documento histórico, pero hubo problemas al ser llevadas a Lima para su proyección:

[...] fue llevada a Lima a mediados del citado año de 1933 por su propietario y filmador con el objeto de exhibirla también en la capital de la República, lo que no fue posible, ya que se había firmado hacía poco el Protocolo de Río de Janeiro, poniendo término al incidente fronterizo entre ambas naciones. No obstante las dificultades surgidas por esa circunstancia, la cinta se exhibió en Palacio, y Wong recibió calurosas felicitaciones por lo bien presentado de la obra [...] (2002, p. 60).

\section{La primera ficción realizada en la Amazonía}

En 1932, Wong se embarcó en la que fue una de las hazañas más intrincadas de su vida, realizar un largometraje de fic-

10 También llamada La Revista de Loreto por otros autores, como Navarro Cáuper. 
ción por el cual es reconocido como un personaje único en el cine peruano. ${ }^{11}$ Antonio Wong estableció un antes y un después en el cine nacional con la realización de Bajo el sol de Loreto, considerada la primera película a colores de largo formato realizada fuera de la capital. Lanzarse a realizar un cine en la Amazonía con una propuesta propia y particular era muy difícil en esos tiempos. Se consideró un hecho icónico, "por atreverse a hacer un largo desde Iquitos, con producción eminentemente local, en una época en la que todo era más complejo, más difícil, más cuesta arriba" (Bardales, 2014, p. 241).

Bardales cuenta que la película fue realizada con una cámara Pathé en 1932 y con una duración de una hora y cuarenta y cinco minutos. Fue estrenada con mucho éxito un año después en los teatros Alhambra y Bolognesi de Iquitos, a través de proyecciones patrocinadas por el Bureau Amazónico de Estudios Sociales y Literarios (2014, p. 241). En su conocida faceta como explorador de nuevas formas y técnicas, Wong coloreó varias escenas de la película con pintura de acuarelas sobre el metraje de película Kodak (p. 241). Con su multifacética personalidad, Antonio Wong realizó esta producción y desempeñó casi todos los roles: camarógrafo, guionista, productor, editor y difusor. También contó con el apoyo técnico de Enrique León Morejón y Julio Baldeón 142 para la realización del film.

11 Algo que la mayoría de gente no conoce de la historia de esta película es que años antes, cuando Wong tuvo su inquietud por la música, empezó a crear y componer algunas canciones, dentro de las cuales creó, con Jorge Runciman, el vals Bajo el sol de Loreto. Esta canción, reconocida hasta la actualidad en la memoria del poblador urbano amazónico loretano, le dio luego el nombre a la película. 
La película tuvo como protagonista a la loretana Deidamia Pinedo Díaz, fue grabada durante seis meses, está ambientada en la época del caucho y narra el periplo de algunos personajes entre caucheros e indígenas:

[...] Para filmar esta obra, ha tenido que trasladarse al río Napo, e internarse en la selva siguiendo el curso del río Tarapoto, afluente de aquel por su margen derecha, hasta ponerse en contacto con la tribu semi-salvaje de los Aushiris, lugar que ha servido de escenario natural al desarrollo de las principales escenas (Navarro Cáuper, 2002, p. 61).

Se recuerda de esta película la filmación de inolvidables crepúsculos de la selva, en donde el paisaje fue retratado en el celuloide como nunca antes había sido visto.

Las copias originales de sus películas se encuentran en un estado lamentable. Bajo el sol de Loreto no puede ser proyectada por esta razón, pues la copia original está muy deteriorada. Sin embargo, los descendientes de Wong están buscando apoyo y restaurando esta pieza clave de nuestra historia cinematográfica.

Luego de esta etapa, Wong siguió incansablemente en la realización fotográfica y cinematográfica y abordó en sus producciones diferentes aspectos como el turismo, la pesca y la promoción cultural. Entre sus cortometrajes más destacados de este periodo resaltan Policromías loretanas, ${ }^{12}$ Luces y sombras de Loreto (1941), Amazonía peruana (1945) y Conozca Loreto (1950) realizados a colores. En 1951, presentó en Lima la exposición fotográfica titulada Conozca Loreto:

12 Este cortometraje fue presentado durante la celebración del IV Centenario del Descubrimiento del Río Amazonas. 
Exposición fotográfica de la selva del Perú, que presentaba su trabajo a través de los paisajes y la sociedad loretana de los ańos cuarenta (Bardales, 2014, p. 242).

\section{Otras producciones de esta etapa}

Otro realizador importante, mencionado en líneas anteriores, es Guillermo Garland Higginson, considerado un importante director de fotografía y realizador de documentales de este periodo. Desde el decenio anterior se registran producciones realizadas por él como La conquista de la sel$v a$, junto a los franciscanos descrita anteriormente y la película La excursión a la montaña de los miembros del Congreso de Turismo, material de 572 metros de longitud restaurada por el proyecto ARCHI, ${ }^{13}$ ambas realizadas en la misma zona en 1929.

En diciembre de 1931 comenzó la producción cinematográfica de esta etapa con la proyección del documental Bajo el cielo peruano, también dirigida por Guillermo Garland. La prensa de la época señala lo siguiente sobre esta película:

[...] Se ve desfilar la montañosa región de Chachamayo, intrincada región de bosques, donde aún las costumbres de la vida civilizada van apenas llegando a medida que la cinta de las carreteras va ganando terreno en aquellas regiones. Los campas muestran sus costumbres y su vida en las extensas zonas de la hoya amazónica (Bedoya, 1997, p. 79).

Luego, llegaron las coproducciones con participación de equipos y financiamiento mixto entre peruanos y extranje-

13 Archivo Peruano de Imagen y Sonido, mencionado en líneas anteriores. 
ros. Se registra que el 29 de octubre de 1937 se estrenó la película Sangre de selva dirigida por Ricardo Villarán con música de Daniel Alomía Robles. Tuvo la participación de los actores españoles Carmen Pradillo, Alejo López, José Luis Romero, Blanca Rowlands y Elvira Travesí. Esta película fue producida por la empresa limeńa Amauta Films y es recordada por la presencia de 50 indios campas que fungieron de extras (Bedoya, 1997, p. 100). La prensa de la época reseñó la película de la siguiente manera:

[...] El Perené, verdadero rincón encantado, agreste, bello y exuberante. Es allí donde se desarrolla y se ha filmado Sangre de selva, presentándonos todas las riquezas extraordinarias que se esconden entre esa marańa selvática, en la que habitan como guardianes de sus tesoros alimañas de todas clases. Paisajes imponentes y de belleza indescriptible desfilan ante los ojos asombrados del espectador de Sangre de selva, obra esencialmente nacionalista, porque ella hace conocer a muchos peruanos su propio país [...] (Diario Universal, 24 de octubre de 1937, citado por Bedoya, 1997, p. 101).

También se mencionan otras iniciativas como la señalada por Joaquín García en la ciudad de Iquitos, donde César Mosquera, un emprendedor y promotor cultural español realizó una serie de actividades para activar la vida cultural de la ciudad y, dentro de ello, abrió un estudio fotográfico en donde realizó "un cine informativo de carácter localista” (1981, p. 177). Bedoya menciona también la película Alerta en la frontera, producida en 1941 por la Nacional Films, ${ }^{14}$ administrada por Federico Uranga, con la direc-

14 Empresa fundada a partir de la experiencia de la productora Amauta Films. 
ción de Kurt Hermann y la participación de los camarógrafos Manuel Trullen y Pedro Valdivieso (1997, p. 141). Esta película mostraba acciones militares del conflicto fronterizo con Ecuador de esos ańos en la zona de la selva norte del país, fue censurada y no llegó a ser exhibida. La prensa de la época comenta: "Tenía el lanzamiento de los paracaidistas en Machala, el cruce del río Zarumilla y muchos aspectos interesantes del conflicto [...] el mismo día del estreno nos prohíben la exhibición. Nos dijeron que era contraproducente el pasarla por cuanto estaba en puertas el arreglo de Río de Janeiro [...]" (Archivo Trullen, citado por Bedoya, 1997, p. 141).

\section{Se cierra el telón}

Es sorprendente darse cuenta, a partir de esta revisión, de las limitadas fuentes que tratan sobre la realidad amazónica. Mas allá de la información recuperada sobre las primeras producciones registradas, es relevante señalar que estas se centran en focos urbanos importantes, como es el caso de la ciudad de Iquitos o la producción que se pudo generar en Lima. No se ha recabado información ni se conoce la realidad de esta etapa en zonas como San Martín, Pucallpa en Ucayali o Puerto Maldonado en Madre de Dios, tomando en cuenta, además, que existían asentamientos en estas zonas desde finales del siglo XIX y principios del XX.

Es claro observar que los primeros registros y producciones fueron impulsados por la dinámica del naciente medio del cine, sobre todo, por la promoción de las productoras francesas y estadounidenses que se dedicaron a enviar operadores para el registro cinematográfico de la realidad en todo el glo- 
bo. Pero más allá de esto, es evidente, en la primera etapa, el provecho que actores políticos y empresariales le dieron al nacimiento de este nuevo medio y a su consecuente uso en beneficio de sus intereses.

Esto lo podemos observar a través de la continua representación de la selva central acorde con los intereses estatales que buscaban expandirse sobre este territorio y apoyar su colonización. También desde la perspectiva de empresas constructoras de infraestructura a gran escala, como es el caso del ferrocarril central, que produjeron registros cinematográficos con el fin de apuntalar su imagen y mostrar positivamente el trabajo que realizaban en estas zonas.

Un hecho icónico al respecto es el rol de Julio César Arana como uno de los primeros productores, sino el primero, del cine realizado en la Amazonía peruana. Su rol resulta fundamental, pues define la carrea de Silvino Santos al financiarlo y enviarlo a Francia para que aprenda la labor de operador de cámara. Este personaje llegó a tener hasta tres productoras cinematográficas con las que buscó limpiar su imagen como abusador y esclavista de indígenas, promocionar sus empresas y captar nuevos capitales extranjeros para sus inversiones.

La relación del cine con la selva en los primeros dos decenios del siglo XX no está lejos de la mirada colonizadora y de la lógica de la penetración de un lugar inhóspito que debe ser gobernado. Un lugar que necesita ser conquistado para poder llegar a tener los frutos que puede brindar, en otras palabras, los recursos que benefician a quien tiene la valentía de entrar en ella. 
A pesar de esto, desde los años treinta esta visión comenzó a cambiar gracias a la motivación e incentivo de nuevos actores en el rol de la producción y representación de esta región. Empezaron a aparecer realizadores como Antonio Wong Rengifo, quien puede ser considerado el pionero del actual movimiento del cine regional, con una mirada localista, pero a la vez urbana de la realidad amazónica. Asimismo, Guillermo Garland, quien desde una mirada centralista y capitalina decidió penetrar esta región en busca de nuevos escenarios. Las posibilidades de la representación o la mirada indígena están aún muy lejanas en el tiempo.

Recibido: 24 de agosto del 2018.

Aprobado: 19 de diciembre del 2018.

\section{Bibliografía}

Bardales, F.

(2007) Comentario del 17 de abril del 2007. Antonio Wong: el hombre que abrazó el sol de Loreto. Cinencuentro. Lima. Recuperado de https:/www.cinencuentro. com/2007/04/17/antonio-wong-el-hombre-queabrazo-el-sol-de-loreto/

Bardales, F.

(2014) Antonio Wong Rengifo: El hombre que abrazó el sol de Loreto. En Iquitos (p. 238). Lima: Telefónica del Perú.

Bedoya, R.

Un cine reencontrado: Diccionario ilustrado de las peliculas peruanas. Lima: Fondo editorial de la Universidad de Lima.

Bedoya, R. (2009)

El cine sonoro en el Perú. Lima: Fondo Editorial de la Universidad de Lima. 
Bedoya, R.

(2009)

El cine silente en Perú. Lima: Fondo Editorial de la Universidad de Lima.

Bedoya, R.

(2015) Comentarios del 23, 27 y 31 de mayo del 2015. La Amazonia en el cine peruano I, II, II y IV. Páginas del diario de Satán. Lima. Recuperado de http:// www.paginasdeldiariodesatan.com/pdds/?p=1500

Bustamante, E.

(2014) El cine en Iquitos. En: Iquitos (p. 230). Lima: Telefónica del Perú.

Chirif, A.; Cornejo Chaparro, M.; y De la Serna Torroba, J.

(2013) Álbum de fotografías: viaje de la Comisión Consultar al Río Putumayo y Afluentes, agosto a octubre de 1912. Lima: Programa de Cooperación Hispano Peruano. Recuperado de https://es.scribd. com/document/326715975/045-Album-de-fotografias-Viaje-Comision-Colsular-al-Rio-Putumayoy-Afluentes-pdf

García, J.

(1981) Historia del cine en Iquitos y en la región. Revista Shupihui, 6 (18), 173.

García, J.

(2014) Cronología histórica del cine en Iquitos desde los orígenes hasta 1980. Iquitos (p. 224). Lima: Telefónica del Perú.

La Serna, J. y Chaumell, J.

(2016) El Bosque Ilustrado: diccionario histórico de la fotografía amazónica peruana (1868 - 1950). Centro Amazónico de Antropología y Aplicación Práctica. Lima.

Navarro Cáuper, L. A.

(2002) El arte de la cinematografía en Iquitos 1898-1942. Kanatari (2).

Ugarte, C.

(2012, 6 de noviembre). Filmoteca de Lima: una mala película, una deuda pendiente. Chaska. Lima. Recuperado de 
https://claudiaugarte.com/2012/12/06/filmotecade-lima-una-mala-pelicula-una-deuda-pendiente/

Vale da Costa, S.

(1987) No rastro de Silvino Santos. Amazonas: Superintendência Cultural do Amazonas.

Valdivia, F.

(2014) Cine documental amazónico: de la representación a la auto-representación. En R. Badini (Ed.), Amazzonia indigena e pratiche de autorappresentazione ( $\mathrm{p}$. 179). Milán: FrancoAngeli. Studi di Lingüística Filologia Letteratura,

\section{Filmografía referenciada}

Benavides, O.

(1915) Entrada a Iquitos de las tropas que participaron en el combate del Caquetá [Cortometraje documental - registro]. Iquitos.

Benavides, $\mathrm{O}$.

(1915) Picnic durante carnavales de 1914 [Cortometraje documental - registro]. Iquitos.

Benavides, O.

(1915) Revista de la vida militar y social [Cortometraje documental - registro]. Iquitos.

Dyott, G.M.

(1921) Crónica filmica de la expedición al Amazonas: Expedición sueco-peruana a las montañas del oriente de Carlos Rospigliosi Vigil y Otto Nordrnskjold. [Largometraje documental - registro]. Ucayali: Cinematográfica Sudamericana. Chanchamayo. (1899). [Cortometraje documental - registro].

Chester, C. L.

Viaje al interior del Perú [Largometraje documental]. Ucayali: Peruvian Corporation. 
The Chuncho Indians of the Amazon River. (1910). [Largometraje documental]. Ucayali: Edison Manufacturing Company.

Fernández, W.

(1924) Misiones dominicas del Perú [Largometraje de ficción]. Cuzco: Misioneros Dominicos.

Garland, G.

(1929) La conquista de la selva. [Largometraje documental]. Chanchamayo, Pachitea: Padres Misioneros Franciscanos Descalzos.

Garland, G.

La excursión a la montaña de los miembros del Congreso de Turismo [Largometraje documental]. Ucayali.

Garland, G.

Bajo el cielo peruano. [Largometraje documental]. San Martín.

García, F.

El socio de Dios [Largometraje de ficción]. Cuzco: Cinematográfica Kuntur S.A.

Hermann, K.

Alerta en la frontera [Largometraje documental]. Frontera con Ecuador. Nacional Films.

Ludwick, V.

Tras los Andes: Hacia el paraíso peruano. [Largometraje documental]. Ucayali: La Colonizadora.

Michiles, A.

O cineasta da selva. [Largometraje docu-ficción]. Filmes. Brasil: Versátil.

Reátegui, A.

(1911) Llegada de las tropas del comandante Benavides a la ciudad de Iquitos [Cortometraje documental - registro]. Iquitos. 
Santos, S.

(1914) Film sin título sobre el rio Putumayo (perdido). PutuSantos, S. mayo: Peruvian Amazon Rubber Company.

(1916)

Indios wuitotos del río Putumayo [Largometraje documental]. Putumayo y Manaos: Peruvian Amazon Rubber Company.

Santos, S.

Escenas amazónicas [Cortometraje documental]. Putumayo: Amazonía Cine-Film.

Santos, S.

El oriente peruano. [Largometraje documental]. Putumayo, Iquitos y Manaos: Amazonía Cine-Film.

Villarán, R.

Sangre de selva. [Largometraje de ficción]. Ucayali: Amauta Films.

Wong Rengifo, A.

(1932-1934) Revista Loretana. [7 cortometrajes documentales]. Iquitos.

Wong Rengifo, A.

(1936) Bajo el sol de Loreto. [Largometraje de ficción], Iquitos.

Wong Rengifo, A.

(1941) Luces y sombras de Loreto. [Cortometraje documental], Iquitos.

Wong Rengifo, A.

Policromías amazónicas. [Cortometraje turístico], Iquitos. 